УДК 82І.ІІ2.2(436)

ББК $83.3(4$ Авс $) 6$

\section{ПОИСКИ НАЦИОНАЛЬНОЙ ИДЕНТИЧНОСТИ В ПРОИЗВЕДЕНИЯХ АВСТРИЙСКИХПИСАТЕЛЕЙ НАЧАЛА ХХ В.}
(C) 2019 г. С.В. Балаева
Санкт-Петербургская государственная художе- ственно-промышленная академия им. А.Л. Штиглии, Санкт-Петербург, Россия Дата поступления статьи: 05 апреля 2019 г. Дата публикации: 25 декабря 2019 г.

DOI: I0.22455/2500-4247-20I9-4-4-72-85

Аннотация: Статья посвящена произведениям австрийских писателей начала $\mathrm{XX}$ в., в центре внимания которых - поиски национальной идентичности. Многие рассматриваемые произведения рассказывают о межнациональных отношениях в австро-венгерской армии, что помогает объяснить обострение этих отношений во время революции г918 г. Рассказчики пытаются понять, что для них важно - история, в которой существует идея единой АвстроВенгрии, или та, в которой этой идеи нет, в которой нет имперской истории и в которой обретают свое существование истории национальные, истории народов, населявших многонациональную империю. В г9г8 г. Австрия потеряла свой статус империи, что заставило многих австрийцев заново искать и находить национальную и культурную идентичность. В статье рассматривается исторический контекст, в котором создаются произведения, затрагивающие тему межнациональной напряженности в Австро-Венгерском обществе начала XX в. В статье анализируется социокультурная ситуация, создавшаяся после окончания Первой мировой войны. В центре статьи произведения австрийских писателей Г. фон Гофмансталя, Ст. Цвейга, Ф.Т. Чокора, Р. Музиля, А. Вильдганса, А. Лернета-Холениа и Й. Рота.

Ключевые слова: идентичность, Австро-Венгрия, Австрия, межнациональный конфликт, революция.

Информация об авторе: Светлана Владимировна Балаева - кандидат филологических наук, заведующий кафедрой гуманитарных и инженерных дисциплин, ФГБОУ ВО «Санкт-Петербургская государственная художественно-промышленная академия имени А.Л. Штиглица», Соляной переулок, д. I3-I5, I9IO28

г. Санкт-Петербург, Россия. ORCID: оооо-о0о3-о8Iо-34Iо

E-mail: svetlana.balaeva@inbox.ru

Для цитирования: Балаева С.В. Поиски национальной идентичности в произведениях австрийских писателей начала XX в. // Studia Litterarum. 20I9. T. 4, № 4. C. 72-85. DOI: 10.22455/2500-4247-2019-4-4-72-85 


\title{
THE QUEST FOR NATIONAL IDENTITY IN THE WORKS OF AUSTRIAN WRITERS AT THE BEGINNING OF THE 20TH CENTURY
}

This is an open access article distributed under the Creative Commons Attribution 4.0 International (CC BY 4.0)

\author{
(C) 20I9. S.V. Balaeva \\ Saint Petersburg State Academy of Art and Design \\ named after A.L. Stieglitz \\ St. Petersburg, Russia \\ Received: April 05, 2019 \\ Date of publication: December 25, 2019
}

Abstract: The article examines literary by the early $20^{\text {th }}$ century Austrian authors, $\mathrm{H}$. von Hofmannsthal, St. Zweig, F.T. Csokor, R. Musil, A. Wildgans, A. Lernet-Holenia and J. Roth, and focuses on the theme of their quest for national identity. Many of the examined works narrate the story of ethnic relations in the Austro-Hungarian army. These narratives convey the tension that existed in the Austro-Hungarian society in the beginning of the $2 \mathrm{o}^{\text {th }}$ century and help us understand how and why the ethnic controversies increased in the time of the I9I8 revolution. The narrators are trying to understand what is more important to them - a history of Austria-Hungarian Empire as a solid state and as a concept, or alternative national histories of ethnic groups that make up for this multinational empire. In I9I8, Austria lost its empire status that forced many Austrians to search for and redefine their national and cultural identity. The article discusses the historical context of these works and analyzes the socio-cultural situation after the end of the World War I.

Keywords: identity, Austria-Hungary, Austria, ethnic conflict, revolution.

Information about the author: Svetlana V. Balaeva, PhD in Philology, Head of the Department of Humanities and Engineering Disciplines, Saint Petersburg A.L. Stieglitz State Academy of Art and Design, Solyanoy I3-I5, 191028 St. Petersburg, Russia.

ORCID: 0000-0003-0810-3410

E-mail: svetlana.balaeva@inbox.ru

For citation: Balaeva S.V. The Quest for National Identity in the Works of Austrian Writers at the Beginning of the $20^{\text {th }}$ Century. Studia Litterarum, 2019, vol. 4, no 4, pp. $72-85$.

(In Russ.) DOI: 10.22455/2500-4247-2019-4-4-72-85 
Одной из важнейших тем австрийской литературы на протяжении двух столетий была и остается тема «австрийскости», т. е. осмысление национальной самобытностиг. Еще в XIX в. поэт Франц Грильпарцер (Franz Grillparzer, I79I-I872) посвятил свою пьесу «Оттокар» (I825) событиям XIII в. - противостоянию богемского короля Пршемысла Оттокара II (І253-I278) и Рудольфа фон Габсбурга (І273-І29I). Рудольф Габсбургский, по замыслу Грильпарцера, должен был представлять тип идеального правителя-австрийца, любящего в первую очередь не себя, а свою страну.

Герман Бар (Hermann Bahr, I863-1934) считал выразительницей национальной сущности столицу Австрии Вену, которую называл «перекрестком культур», вбирающим в себя немецкую, итальянскую, испанскую, славянскую и еврейскую культуры [2, с. 32]. В эссе «Вена» (I906) австрийский писатель отмечает искусственность венцев, которые похожи на актеров, носящих маски, но, возможно, не имеющих души. Как указывает А.А. Стрельникова, образ венца, по Г. Бару, состоит в том, чтобы «быть всегда актером без собственного “я” [2, с. 33].

Позже уже Гуго фон Гофмансталь (Hugo von Hofmannsthal, I874I929) попытался описать суть австрийского мироощущения. Он сделал это в сопоставлении австрийского и немецкого характера. Австрийский поэт не противопоставлял немецкую («прусскую») культуру и австрийские тради-

I Проблема национальной идентичности остается одной из самых значимых в австрийском обществе и сегодня. Исторические потрясения, испытанные австрийцами в XX в., снова и снова заставляют их возвращаться к вопросу о собственной самобытности. В частности, проблеме национальной идентичности в современной австрийской литературе посвящена кандидатская диссертация А.В. Плахиной «Романы Кристофа Рансмайра и своеобразие австрийской прозы І980-х - І990-х. К проблеме национальной идентичности» (2007) [г]. 
ции. Его интересовало их взаимодействие, при том, что поэт в созданной им схеме «Пруссак и австриец» (I9I7) постарался сформулировать качества, присущие австрийцам и немцам [9, с. 459-46I]. Гофмансталь назвал австрийцев более гуманными и чувствительными, а немцев расчетливыми и мыслящими абстрактно. С другой стороны, поэт указал на немецкую дисциплинированность, а австрийцам приписал жажду удовольствий и тягу к лицедейству. Австрийцев от немцев отличает, по мысли Гофмансталя, любовь к своей родине и верность Габсбургам.

Чуть позже Стефан Цвейг (Stefan Zweig, I88I-I942) ретроспективно описал различия между немецкой и австрийской идентичностью. Отличительной чертой австрийской жизни Цвейг называет «легкий, непринужденный, расточительный размах», противопоставляя его немецкой скупости, «чистоте и строгому порядку» [3, с. І25-126]. А далее писатель для большей наглядности сравнивает венскую и берлинскую домохозяек, причем австрийка предстает «бойкой, болтливой», «легкомысленной» женщиной, всегда готовой прийти на помощь, а немка - точной, корректной, учитывающей «каждую мелкую услугу, которую она оказала» [3, с. І26].

Эти наблюдения предстают во многом как поверхностное, частное страноведение, основанное на стереотипном понимании различий между австрийцами и немцами.

В культурном плане австрийцы при этом должны были стать в Европе выражением немецкого духа. Так, Гофмансталь утверждал, что австрийская литература принадлежит к единой немецкой: «...насколько существует Австрия и австрийская суть и насколько сильно я себя сознаю австрийцем, настолько мало существует и вряд ли существует вообще австрийская литература, и настолько неприемлемо кажется мне быть кем-то иным, чем немецким поэтом из Австрии» [I4, с. I5]. Впрочем, по мысли поэта, «Австрия для Востока и Юга - дающая страна, а для Запада и Севера - принимающая» [Іо, с. 394], находящаяся на пересечении четырех сторон света.

Немецкий элемент в австрийском обществе выделял и Франц Теодор Чокор (Franz Theodor Csokor, I885-1969). Известный австрийский драматург посвятил событиям распада империи пьесу «3 ноября I9I8 года» (1936). 3 ноября г918 г. - тот день, в который австро-венгерское армейское командование вынуждено было объявить о перемирии, так как процесс распада империи было невозможно остановить [ІІ, с. 66]. Один из иссле- 
дователей назвал эту пьесу Чокора «лучшим примером изображения часа прощания с монархией» [ІІ, с. 85].

Драма «3 ноября І9І8 года» возникла в сложные политические времена как реакция на них. Когда Чокор зимой І935 г. принимался за написание этой пьесы, то он намеревался дать ей другое название - «Погребение» (Grablegung) [19, с. 30]. Драматург создавал эту драму как свидетель, как офицер императорской армии, переживший конец империи. В пьесе Чокор показывает, как по-разному офицеры различных наций империи переживают этот исторический момент. Старослужащий офицер, единственный приверженец наднациональной идеи умирающей империи, оказывается в жесткой конфронтации с реальностью и накладывает на себя руки.

Момент погребения в пьесе оказывается знаковым: боевые товарищи бросают в его могилу землю со словами, демонстрирующими, что прошлая имперская общность навсегда разрушена. Каждый согласно своему происхождению произносит: «Земля из Венгрии! Земля из Польши! Земля из Каринтии! Словенская земля! Чешская земля! Римская земля!» Только еврейский полковой врач говорит: «Земля из... земля из... Австрии» [I9, с. 3I].

Автор пьесы утверждал, что представляет собой часть единого народа, в нем текла кровь, в которой, по его собственному утверждению, «смешались немецкий, славянский, венгерский и латинский элементы» [II, c. 65]. Немецкая кровь оказывается у Чокора на первом месте, сербская скрывается за общим обозначением «славянской», латинская придумана, а о еврейской он вообще умолчал [Іі, с. 65-66]. Пьеса «3 ноября І9г8 года» стала представлением «разных народов в их отношении к модели немецкой культуры, их разнообразных суждений по этой проблеме» [ІІ, с. 67].

По мнению многих авторов, австрийская идентичность самостоятельна и напрямую восходит к ощущению австрийцами себя как конгломерата многих народностей, многих культурных традиций.

В романе Йозефа Рота (Joseph Roth, I894-I939) «Марш Радецкого» (1932) Вена предстает как имперский город. Стремящиеся же к самостоятельности, отстаивающие собственные интересы венгры выглядели в представлении Рота разрушителями империи. Австрия у Рота была носителем наднациональной идеи, исключающей любые внутренние границы. Подобные характеристики, даваемые австрийскими писателями, стоит все же вос- 
принимать критически, поскольку они представляют собой ретроспективный взгляд на австрийскую имперскую идентичность.

Понятие австрийской идентичности тесно связано с определением самобытности и самодостаточности австрийской литературы, которую очень долго вписывали в «пангерманский» контекст. В І9І8 г. Й. Надлер выпустил в свет первое издание «Литературной истории немецких племен и ландшафтов», которая была положительно воспринята в литературных кругах, в частности, Г. Баром и Г. фон Гофмансталем [24, с. 645]. Надлер создавал свою «Историю» в противовес голосам приверженцев независимой Австрийской республики.

Однако в Австро-Венгрии существовали области, жители которых в мыслях все чаще обращались к Германии, сознательно или подсознательно видя в ней истинную родину, вернее, прародину. Возможно, именно поэтому, чтобы приблизиться к истинно германскому мироощущению, в Штирии, Каринтии и Судетской области многие австрийцы переходили в протестантизм, поскольку он считался истинно немецкой религией. Число австро-венгерских протестантов в начале XX в. не превышало полумиллиона человек. Интересно, что семейные корни известного австрийского писателя Александра Лернета-Холениа (Alexander Lernet-Holeina, I897-I976) были в Каринтии, а по рождению он был протестантом. Тем знаменательнее тот факт, что писатель в І924 г. перешел в католическую веру, которая считалась одной из составляющих австрийского самосознания, таким образом он подчеркивал свою австрийскость.

Проблема идентичности после окончания Первой мировой войны представала одной из центральных, поскольку в центре общего внимания оказался вопрос о будущем страны. Австрийцы колебались между стремлением к германским корням, космополитизмом и собственно австрийскостью, и, возможно, именно эта неустойчивость и определяет австрийское самосознание в первой трети XX в.

Австро-Венгрия исчезла с политической карты мира І2 ноября I9I8 г., когда была провозглашена «Немецко-Австрийская республика». Таким образом, эту дату можно считать не только основанием новой австрийской республики, но и концом габсбургской монархии. В политических и культурных австрийских кругах присутствовало желание тут же присоединить Австрию к Германии, и в декларации, провозглашавшей появление нового 
государства, в статье № 2, новое государственное образование именовалось «составной частью немецкой республики» [22, с. 4].

Новообразованная Австрия была нежизнеспособна, это было связано с экономической ситуацией, но более существенно было то, что австрийцы по-разному понимали свою роль в Европе, свою культурную самобытность, свое отличие от других народов, например, от немцев Германии. Различные наименования Первой республики - «Немецкая Австрия» (Deutschösterreich, I9I8) и «Австрийская республика» (Republik Österreich, I9I9) - иллюстрируют расхождения в отношении к новообразованному государству. В этом смысле очевидно, что «австрийская нация» была в большей степени ориентирована на социально-политическую организацию и в меньшей степени - на язык и этнос.

Сразу после распада Австро-Венгрии в обществе царили различные настроения, австрийцы по-разному видели будущее своей страны. Это были и вера в многонациональность, и в монархию, и в немецкий национализм, и в идеалы социалистического интернационализма, и, наконец, представление о том, что Австрия должна стать центром европейской культуры, что, впрочем, было еще одним «ложным способом обращения с историей» [ı8, c. 8I]. В то же время два влиятельных общественно-политических лагеря Первой республики - социал-демократы и христианские социалисты не стремились определить сущность австрийской идентичности. Тогда же австрийский философ-социалист Альфред Клар (Alfred Klahr, I904-I944) писал: «В Австрии нет национального вопроса в привычном смысле слова. <...> Австрия не была, как Данциг или Саарская область, частью Германской империи (после ее объединения в г87г году), которая была бы оторвана от нее. <...> Когда речь идет о национальной принадлежности австрийского народа, то ответ таков: австрийский народ “само собой” является частью немецкой нации. Это важнейший вопрос, который необходимо прояснить, поскольку такой ответ связан с языком и культурной общностью, имеются в виду языковые и культурные связи между Германией и Австрией, которые позволяют объединять их в один народ» [г6].

Определение идентичности напрямую связано с историографией, поскольку историческое повествование создает предпосылки для определения коллективной идентичности людей, живущих в одном государстве, направляет их мысли и действия, создает из множества разрозненных инди- 
видов единый народ и связывает его системой обязательств. Как утверждает Э. Балибар, «история народов является повествованием, представляющим их существование в виде разматывающейся нити» [4, с. Iо7].

Однако вопреки усилиям некоторых влиятельных общественных деятелей в Австрии, например, католического публициста Эрнста Карла Винтера или философа Альфреда Клара, который в 1937 г. в газете «Путь и цель» предпринял попытку теоретически обосновать австрийскую самобытность, в тридцатые годы в австрийской республике не существовало ощущения единства нации [5]. Об особенном ощущении отсутствия национального чувства писал Роберт Музиль (Robert Musil, I880-1942) в эссе «Немец как симптом» (I925), в котором отразил раздвоенность национального самосознания на «австрийское» и «немецкое».

В 1928 г. Гуго фон Гофмансталь заметил в одном из писем, что даже такого поистине австрийского поэта, как Рильке, необходимо рассматривать как представителя немецкой, но не австрийской литературы [I4, c. I5]. Другой известный австриец и литератор отстаивал прямо противоположную точку зрения: драматург Антон Вильдганс (Anton Wildgans, I88I-I932) в 1929 г. обратился к проблеме национальной идентичности в своей «Речи об Австрии» [23], еще раз сформулировав основные черты «австрийскости». Вильдганс назвал Австрию «преддверием Азии», средоточием фантастического множества народов, притом что «гегемония немецкости» подошла к концу еще в начале девятнадцатого века. Отношение австрийцев к истории было сформировано тем фактом, что много столетий подряд они оказывались непосредственными участниками великих событий и расплачивались за это кровью. Вильдганс говорит и о решающей роли римско-католической церкви: «Австрийцы - в большинстве приверженцы римско-католической церкви, которая означает со своей стороны школу наднациональной, универсальной идеи, определенного типа мышления, чувствования и служения» [23]. Автор «Речи» не отрицает решающей роли немецкого происхождения австрийских немцев, но делает акцент на том, что эта немецкость «из-за смешения многих кровей и по историческому опыту менее однозначна и однородна, но при этом более <...> европейская» [23].

Своеобразный итог размышлениям об имперской австрийской идентичности подвел историк Генрих фон Србик (Heinrich von Srbik, I878-1951). Он утверждал, что австрийская идентичность является одним из частных 
случаев, своего рода «пережитком» ощущения себя частью Священной Римской империи германский нации [20, с. 9-1о]. В сборнике «Австрия. Ее место и назначение в германском пространстве» Србик заявил об исключительном положении Австрии, поскольку она определяет судьбу всего германского народа. Србик видел возможность идеального воплощения австрийской империи во времена Третьего Рейха, о чем заявил в своих исторических исследованиях [2I].

В І94I г. в Берлине вышло в свет четвертое издание работы Й. Надлера «Литературная история немецкого народа, литература и письменность немецких племен». Надлер констатировал, что в I9I8 г. произошел перелом в сознании народов Германии и Австрии, ставший предпосылкой для возрождения идеи о едином немецком народе. Австрийцы должны были стать его частью не только политически, но и культурно - в этом состоит основная цель истории. Надлер подчеркивал историческую неизбежность интеграции новой австрийской литературы в немецкое культурное пространство и вписал в него Гофмансталя и Бара, а также более молодых авторов - Макса Мелля, Роберта Музиля и Александра Лернета-Холениа [24, c. 648]. Идеологический подтекст работы Надлера очевиден, ее целью было представление необходимого Третьему Рейху обоснования состоявшегося ранее «аншлюса» Австрии к Германии.

Декларационное заявление Надлера о неизбежном объединении австрийского и немецкого культурного пространства контрастирует с заявлением эмигрировавшего из Германии Томаса Манна (Thomas Mann, I875-1955), который на вопрос «Существует ли австрийская литература?» в 1936 г. ответил однозначно: «Вы спрашиваете меня, можно ли говорить о специфической австрийской литературе. Утвердительный ответ очевиден. Специфические особенности австрийской литературы, правда, не так просто определить, но каждый обнаружит их, и если это страшное время не уничтожит в нем последние остатки симпатии к культурной мягкости и духовную прелесть, то он полюбит эти несомненные особенности» [15, c. I94]. Данные особенности Томас Манн выводит из австрийской многонациональности.

Представления об «австрийскости» наиболее полно отражены в литературных произведениях межвоенного периода. Йозеф Рот в «Марше Радецкого» назвал Австро-Венгерскую империю единственной сверхнацией, 
которая когда-либо существовала на земле. В этом романе Рота габсбургская империя существует более всего в сознании отдельных людей. Как только они теряют веру в имперский порядок, то оказываются в конфронтации с миром и самими собой [8, с. I38].

Роберт Музиль, современник Й. Рота, в своем романе «Человек без свойств» также обращается к проблеме австрийской идентичности. Австро-Венгерская империя - «Какания» - изображена автором как вместилище нереализованных возможностей [6, с. 89]. Герои становятся заложниками переплетенных с фантазиями воспоминаний о прошлом, и, как им кажется, нереализованные когда-то возможности проецируются в будущее и принимают утопический характер [І2, с. Іо4-І05]. Австро-Венгрия в романе Музиля предстает как нечто среднее между крайностями, она не представляет собой ни великое, сильное государство, ни слабое, карликовое. Человеческие стремления австро-венгерских подданных были «умеренными», таким образом, страна таила в себе многие свойства, но не имела никаких специфических качеств, которые ее выделяли бы; так что Музиль отмечал в своих дневниках: «Какания - это государство “как, так и” и “ни ни” [І2, с. Іо2]. Один из исследователей творчества писателя отметил, что для Музиля современная австрийская жизнь не предполагала наличия подлинных героев, а все происходящее было не результатом волевых усилий отдельных личностей, а лишь стечением обстоятельств [7, с. 3]

Произошедший в Австрии в 1934 г. политический переворот открыл возможность возрождения старой габсбургской традиции, был возвращен старый герб - двуглавый орел - и военная форма габсбургской армии [I7, c. 3I]. Вновь была объявлена государственная идея - стать «мостом» между нациями, но это не означало, что тем самым конституировалось национальное австрийское самосознание.

В романе А. Лернета-Холениа «Штандарт» (1934), создававшемся параллельно с происходящими политическими переменами, в определенной степени отразились эти взгляды, хотя рассказчик обращает свои слова не ко времени Второй республики, а к событиям конца Первой мировой войны. В этом произведении один из офицеров императорской австро-венгерской армии объясняет немецкому дворянину, как глубоко в души солдат проникла идея многонациональности: «Наша армия никогда не воспримет националистские призывы, ведь столько народов образуют ее. Очень часто 
нашей армии приходилось выступать против народов, выходцы из которых служат в ее рядах. Ни один не отказался. <...> Мы стоим друг за друга, за империю, насколько можем» [І3, с. г2о]. Эти слова оказываются не только откликом на события внутри страны, но и ответом на нацизм, ставший с I933 г. государственной идеологией в Германии - в стране, с которой Австрия всегда была тесно связана не только общим немецким языком, но и неразрывными культурными нитями.

\section{Список литературы}

I Плахина A.B. Романы Кристофа Рансмайра и своеобразие австрийской прозы I980-х - I990-х. К проблеме национальной идентичности: автореф. дис. ... канд. филол. наук. M., 2007. URL: http://imli.ru/index.php/component/content/ article?id=I559:avtoreferat-plahinoj-av (дата обращения: о4.04.2019). Стрельникова А.А. «...Юди, выдуманные властями»: венская идентичность в размышлениях Германа Бара // Художественное осмысление действительности в зарубежной литературе. М.: Изд-во МГОУ, 2ог7. С. 30-36.

3 Цвейг С. Вчерашний мир. М.: Радуга, г99г. 542 с.

4 Balibar E., Wallenstein J. Rasse, Klasse, Nation. Ambivalente Identitäten. Hamburg: Argument Verlag, I988. $279 \mathrm{~S}$. Burger R. Die nachträgliche Nation. Gedanken zu einer unvollständigen Gegenwart // Zukunft denken. Festschrift für Wolfgang Schüssel. Wien: Böhlau Verlag, 2005.

S. $21-38$.

6 Düsing $W$. Erinnerung und Identität. Untersuchungen zu einem Erzaehlproblem bei Musil, Döblin und Doderer. München: Fink, 1982. 26I S.

$7 \quad$ Goebel E. Konstellation und Existenz: Kritik der Geschichte um I930: Studien zu Heidegger, Benjamin, Jahnn und Musil. Tübingen: Stauffenburg-Verlag, I996. 263 S.

8 Heizmann J. Joseph Roth und die Ästhetik der Neuen Sachlichkeit. Heidelberg: Mattes, I990. I65 S.

9 Hofmannsthal H.v. Preusse und Österreicher // Hofmannsthal H.v. Reden und Aufsätze II. Frankfurt am Main: Fischer Taschenbuch Verlag, I979. S. 459-46I. Hofmannsthal H.v. Wir Österreicher und Deutschland // Hofmannsthal H.v. Reden und Aufsätze II. Frankfurt am Main: Fischer Taschenbuch Verlag, I979. S. 390-396. Konstantinović Z. Franz Theodor Csokors Stück ‘Der 3. November I9I8' // Immer ist Anfang: der Dichter Franz Theodor Csokor. Bern, Frankfurt am Main, New York, Paris: P. Lang, I990. S. 65-74. Eigenschaften“ // Robert Musils „Kakanien“ — Subjekt und Geschichte. München: Fink, I987. S. 95-II5. 
I3 Lernet-Holenia A. Die Standarte. Wien: Paul Szolnay, I977. 288 S.

I4 Literatur aus Österreich, Österreichische Literatur, ein Bonner Symposion. Bonn: Bouvier, I98I. 24I S.

I5 Mann Th. Werke. Das essayistische Werk. Frankfurt am Main: Fischer, 1980. 339 S.

I6 Marek F. Der theoretische Begründer der “österreichischen Nation”, Dr. Alfred Klahr, I904-I944. URL: http://www.antifa-info.at/archiv/KLAHR.PDF (дата обращения: 04.04.2019)

I7 Rasky B. Erinnern und Vergessen der Habsburger in Österreich und Ungarn nach I9I8 // Österreich I9I8 und die Folgen. Geschichte, Literatur und Film. Wien, Köln, Weimar, 2009. S. 25-58.

I8 Rauchensteiner M. Österreich im Ersten Weltkrieg I9I4-I9I8 // Österreich im 20. Jahrhundert. In 2 Bdn. Bd. I. Wien, I997. S. 57-84.

I9 Sebestyen G. Wort mit Gelächter. Der Dramatiker Franz Theodor Csokor // Lebensbilder eines Humanisten. Ein Franz Theodor Csokors-Buch. Wien, München: Löcker, I992. S. 28-32.

20 Srbik H.v. Das österreichische Kaisertum und die Heilige Römische Reich. Berlin: Dt. Verl. Ges. Fur Politik u. Geschichte, I927. 210 S.

2I Srbik H.v. Österreich im Heiligen Reich und im Deutschen Bund // Österreich. Seine Erbe und Sendung im deutschen Raum. Leipzig, I936. S. I2I-I40.

22 Staatgesetzblatt für den Staat Deutschösterreich, I9I8. Nr. 45. URL: // http://alex. onb.ac.at/cgicontent/alex?aid=sgb\&datum=I9I8\&page=I\&size=45 (дата обращения: 04.04.2019).

23 Wildgans A. Rede über Österreich. URL: http://www.antonwildgans.at/page87.html (дата обращения: 04.04.2019).

24 Zeman H. Die Literatur Österreichs. Eigenart Literaturhistorischer Entfaltung und mitteleuropäisch-donauländischer Standort // Geschichte der Literatur in Österreich von den Anfängen bis zur Gegenwart. In 7 Bdn. Bd. 7. Graz, I999. S. 639-684. 


\section{References}

Plakhina A.V. Romany Kristofa Ransmaira i svoeobrazie avstriiskoi prozy I980-kh - I990-kh. K probleme natsional'noi identichnosti: avtoref. dis. ... kand. filol. nauk [The novels by Christoph Ransmayr and the originality of Austrian fiction of the I980s-I990s. On the question of national identity: $\mathrm{PhD}$ thesis, summary]. Moscow, 2007. Available at: http://imli.ru/index.php/component/ content/article?id=I559:avtoreferat-plahinoj-av (Accessed o4 April 20I9) (In Russ.) Strel'nikova A.A. “...Liudi, vydumannye vlastiami”: venskaia identichnost' v razmyshleniiakh Germana Bara [“...Von Oben Fingierte Menschen”: Viennese identity in Hermann Bar's work]. Khudozhestvennoe osmyslenie deistvitel'nosti v zarubezhnoi literature [Aesthetic interpretation of reality in foreign literature]. Moscow, Izd-vo MGOU Publ., 20I7, pp. 30-36. (In Russ.)

Tsveig S. Vcherashnii mir [Zveig S. Yesterday world]. Moscow, Raduga Publ., I99I. 542 p. (In Russ.)

Balibar E., Wallenstein J. Rasse, Klasse, Nation. Ambivalente Identitäten. Hamburg, Argument Verlag, I988. 279 S. (In German)

Burger R. Die nachträgliche Nation. Gedanken zu einer unvollständigen Gegenwart. Zukunft denken. Festschrift für Wolfgang Schüssel. Wien, Böhlau Verlag, 2005. S. 2I-38. (In German)

Düsing W. Erinnerung und Identitaet. Untersuchungen zu einem Erzaehlproblem bei Musil, Döblin und Doderer. München, Fink, 1982. 26I S. (In German)

Goebel E. Konstellation und Existenz: Kritik der Geschichte um I930: Studien zu Heidegger, Benjamin, Jahnn und Musil. Tübingen, Stauffenburg-Verlag, I996. 263 S. (In German) Heizmann J. Joseph Roth und die Ästhetik der Neuen Sachlichkeit. Heidelberg, Mattes, I990. I65 S. (In German)

Hofmannsthal H.v. Preusse und Österreicher. Reden und Aufsätze II. Frankfurt am Main, Fischer Taschenbuch Verlag, 1979. S. 459-46I. (In German) Hofmannsthal H.v. Wir Österreicher und Deutschland. Reden und Aufsätze II. Frankfurt am Main, Fischer Taschenbuch Verlag, 1979. S. 390-396. (In German) Konstantinović Z. Franz Theodor Csokors Stück 'Der 3. November I9I8'. Immer ist Anfang: der Dichter Franz Theodor Csokor. Bern, Frankfurt am Main, New York, Paris, P. Lang, I990. S. 65-74. (In German) Kümmerling B. Märchenreize. Zur Märchenthematik in Musils „Mann ohne Eigenschaften“. Robert Musils „Kakanien“ - Subjekt und Geschichte. München, Fink, I987. S. 95-II5. (In German)

I3 Lernet-Holenia A. Die Standarte. Wien, Paul Szolnay Verlag, I977. 288 S. (In German)

I4 Literatur aus Österreich, Österreichische Literatur, ein Bonner Symposion. Bonn, Bouvier, I98I. 24I S. (In German) 
I5 Mann Th. Werke. Das essayistische Werk. Frankfurt am Main, Fischer, I980. 339 p. (In German)

I6 Marek F. Der theoretische Begruender der "österreichischen Nation”, Dr. Alfred Klahr, I904-I944. Available at: http://www.antifa-info.at/archiv/KLAHR.PDF (Accessed o4 April 2019). (In German)

I7 Rasky B. Erinnern und Vergessen der Habsburger in Österreich und Ungarn nach I9I8. Österreich I9I8 und die Folgen. Geschichte, Literatur und Film. Wien, Köln, Weimar, 2009. S. 25-58. (In German)

I8 Rauchensteiner M. Österreich im Ersten Weltkrieg I9I4-I9I8. Österreich im 20. Jahrhundert. In 2 Bdn. Bd. I. Wien, I997. S. 57-84. (In German)

I9 Sebestyen G. Wort mit Gelächter. Der Dramatiker Franz Theodor Csokor. Lebensbilder eines Humanisten. Ein Franz Theodor Csokors-Buch. Wien, München, Löcker, I992. S. 28-32. (In German)

20 Srbik H.v. Das österreichische Kaisertum und die Heilige Römische Reich. Berlin, Dt. Verl. Ges. Fur Politik u. Geschichte, I927. 210 S. (In German)

2 I Srbik H.v. Österreich im Heiligen Reich und im Deutschen Bund. Österreich. Seine Erbe und Sendung im deutschen Raum. Leipzig, I936. S. I2I-I4O. (In German)

22 Staatsgesetzblatt für den Staat Deutschösterreich, I9I8. Available at: http://alex.onb. ac.at $/$ cgi-content/alex?aid $=$ sgb\&datum $=$ I9I8\&page $=\mathrm{I} \&$ size $=45$ (Accessed 04 April 20I9). (In German)

23 Wildgans A. Rede über Österreich. Available at: http://www.antonwildgans.at/page87. html (Accessed o4 April 20I9). (In German)

24 Zeman H. Die Literatur Österreichs. Eigenart Literaturhistorischer Entfaltung und mitteleuropäisch-donauländischer Standort. Geschichte der Literatur in Österreich von den Anfängen bis zur Gegenwart. In 7 Bdn. Bd. 7. Graz, I999. S. 639-684. (In German) 